\title{
Neurologic Complications of Human Immunodeficiency Virus-type 1 Infection
}

\begin{abstract}
A wide variety of neurologic complications associated with human immunodeficiency virus-type 1 (HIV-1) infection result from HIV-1 itself or secondarily related to immunosuppression. In Korea, the number of HIV-1 seropositive populations is increasing, but little has been known about the neurologic complications of HIV1 infection. To investigate the neurologic complications in HIV-1 infected Korean patients, we performed a cross-sectional study in consecutive admissions to the Seoul National University Hospital between March 1998 and June 1999. Thirtyfour HIV-1 seropositive patients were included. As a result, a total of $26 \mathrm{HIV}-1$ related neurologic complications were identified from 17 patients. Among them, 10 patients showed cognitive/motor abnormalities: 3 HIV-1-associated dementia and 7 possible HIV-1-associated minor cognitive/motor disorder. Neuromuscular complications were found in 10 patients: 9 distal symmetric polyneuropathy, and 1 possible chronic inflammatory demyelinating polyradiculoneuropathy. In 3 patients with focal brain lesions, 2 were presumptively diagnosed as having primary CNS lymphoma, and 1 as having progressive multifocal leukoencephalopathy in the posterior fossa, based on history, clinical findings, serology, radiological appearances, and response to empirical therapy. Other complications included cryptococcal meningitis and only soft neurologic signs without any neurologic disease. Most of these complications (88\%) occurred in the advanced stage of infection.

Key Words : HIV; Acquired Immunodeficiency Syndrome; Neurologic Manifestations; Neuromuscular manifestations; Korea
\end{abstract}

\author{
Ho Jin Kim, SangYun Kim, \\ Kyung-Bok Lee, Kwang-Woo Lee, \\ Myoung-don $\mathrm{Oh}^{\star}$, Kangwon $\mathrm{Choe}^{\star}$ \\ Department of Neurology and Internal Medicine* \\ Seoul National University College of Medicine, \\ Seoul National University Hospital, Seoul, Korea
}

Received: 2 December 2002

Accepted: 5 February 2003

\section{Address for correspondence}

SangYun Kim, M.D.

Department of Neurology, Seoul National University College of Medicine, 28 Yongon-dong, Jongno-gu, Seoul 110-744, Korea

Tel : +82.2-760-2827, Fax : +82.2-3672-7553

E-mail : neuroksy@snu.ac.kr

\section{INTRODUCTION}

Since the first cases of acquired immunodeficiency syndrome (AIDS) were recognized in 1981 (1, 2), it has developed into a global pandemic. The World Health Organization estimated that approximately 42 million people worldwide have been infected with the human immunodeficiency virus type 1 (HIV-1), and 16,000 new infections occur each day (3). In association with HIV-1 infection, a wide variety of neurologic complications are now recognized, which resulted from opportunistic infections and neoplasm as well as direct effects of virus itself acting alone or with as yet unknown cofactors. These complications occur at all stages of infection and involve any level of central and peripheral nervous system (4-6). Approximately at least $10 \%$ of patients present with a neurologic complaint (5-7), 30 to 50\% develop neurologic complications during the course of the disease (4-6), and up to $90 \%$ show pathologic evidence of neurologic disease at autopsy (8-12).

In Korea, the number of HIV-1 seropositive populations is increasing every year. As of June 1999, the cumulative number of documented HIV-infected patients in Korea was 964, with 208 deaths (13). However, little has been known about the neurologic complications of HIV-1 infection in our population. We report here our experience of neurologic complications in the HIV-1 seropositive Korean patients and describe the characteristic clinical features and relative frequencies of the various neurologic complications.

\section{MATERALS AND METHODS}

A total of 34 patients with HIV-1 infection who admitted to the Seoul National University Hospital between March 1998 and June 1999 were included. HIV-1 infection was ascertained by a combination of ELISA and Western blot. All patients were interviewed and examined by one neurologist. A full neurologic examination and peripheral nerve conduction study (NCS) were performed in all patients. Other diagnostic studies including detailed neuropsychologic test, neuroimaging, cerebrospinal fluid (CSF) study, electromyography (EMG), and neuropathologic study were performed in selected patients. For clinical staging of these patients, we used the "1993 revised classification system for HIV infection 
Table 1. 1993 revised classification system for HIV infection and expanded surveillance case definition for AIDS among adolescents and adults

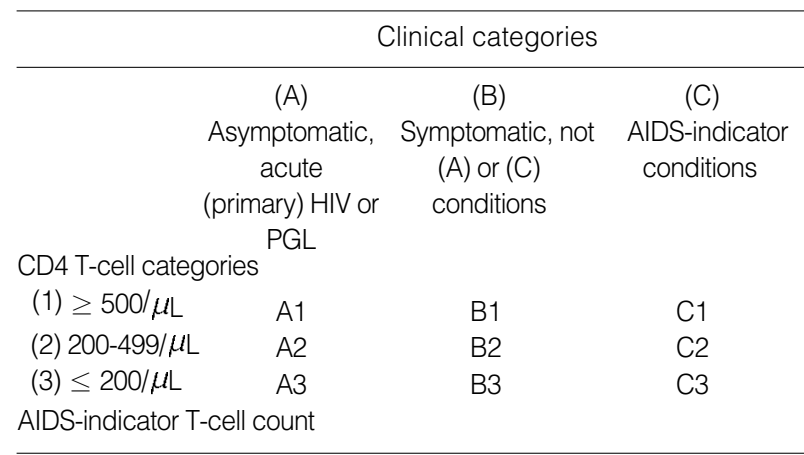

PGL: persistent generalized lymphadenopathy.

Clinical category $C$ includes the clinical conditions listed in the AIDS surveillance case definition.

and expanded surveillance case definition for AIDS among adolescents and adults" (Table 1) (14).

The diagnosis of HIV-1-associated cognitive/motor complex was made on the basis of evidence of acquired impairment in at least two cognitive domains without any evidence of a cerebral mass lesion or active central nervous system (CNS) infection. We divided them into two categories by their severity of impairment in activities of daily living: a more severe form (HIV-1-associated dementia complex, HIV dementia) and a less severe form (HIV-1-associated minor cognitive/ motor disorder, HIV MCMD) (15). Peripheral neuropathy was diagnosed on the basis of clinical symptomatology and electrophysiologic study. In patients with focal brain lesions, the diagnosis was made based on history, clinical and serologic findings, radiological appearances, and response to empirical therapy. Cryptococcal meningitis was diagnosed by detection of its antigen in the patient CSF.

\section{RESULTS}

\section{Demographic and general features}

Of the 34 patients evaluated, 29 were male and 5 were female; 23 of the male patients were heterosexual and 5 were homosexual or bisexual. Of the 5 female patients, 3 were heterosexual and 1 was a transfusion-related case. None had a history of intravenous drug use. The mode of transmission was not identified in one male and one female patient. Their ages ranged from 23 to $68 \mathrm{yr}$, with a mean of $43 \mathrm{yr}$ ( 44 for males and 38 for females). The mean duration of HIV-1 seropositivity was 40 months. By the "1993 revised classification system for HIV infection" 22 were at the clinical stage $\mathrm{C} 3$ and 12 were at the clinical stage less than $\mathrm{C} 3$ (C2:3, C1:1, B2:3, B1:2, A3:1, A2:1, A1:1).

A total of 26 HIV-1-related neurologic complications were
Table 2. Twenty-six neurologic complications of HIV-1 infection experienced in 17 patients

\begin{tabular}{lcc}
\hline & \multicolumn{2}{c}{ Clinical stage } \\
\cline { 2 - 3 } & $\begin{array}{c}\mathrm{C} 3 \\
(\mathrm{n}=23)\end{array}$ & $\begin{array}{c}\mathrm{A} 1 \text { to } \mathrm{C} 2 \\
(\mathrm{n}=3)\end{array}$ \\
\hline $\begin{array}{l}\text { HIV-1-associated dementia complex } \\
\text { HIV Dementia }\end{array}$ & 3 & \\
HIV MCMD & 6 & 1 \\
Neuromuscular Complication & & \\
DSP & 8 & 1 \\
CIDP & 1 & \\
Focal CNS lesions & & \\
$\quad$ PML & 1 & \\
Primary CNS lymphoma & 2 & \\
Others & \\
$\quad$ Cryptococcal meningitis & 1 & \\
$\quad$ Soft neurologic signs only & 1 & 1 \\
\hline
\end{tabular}

HIV dementia: HIV HIV-1-associated dementia complex, HIV MCMD: HIV-1-associated minor cognitive/motor disorder, DSP: distal symmetric polyneurpathy, CIDP: chronic inflammatory demyelinating polyneuropathy, PML: progressive multifocal leukoencephalopathy, CNS: central nervous system.

identified from the 17 patients: 23 neurologic complications out of 15 patients at the clinical stage $\mathrm{C} 3$ and 3 out of $2 \mathrm{pa}-$ tients at the clinical stage less than C3. Eight patients (24\%) had multiple neurologic complications. Six patients $(18 \%)$ had neurologic abnormalities as one of the main complaints and $3(9 \%)$ as initial complaints. The neurologic complications experienced in these patients are outlined in Table 2.

\section{HIV-1-associated cognitive/motor complex}

\section{CASE 1}

A 33-yr-old HIV-1-seropositive man with a history of herpes zoster and postherpetic neuralgia 2 yr earlier was admitted for evaluation of slowness of speech and movement for 6 months. In addition to psychomotor slowing, he complained of forgetfulness for a day-to-day event and painful paresthesia on his soles. Also he had briefly lost his consciousness twice.

Routine bedside Mini-Mental Status Examination (MMSE) was normal. However, he required additional time and effort to complete a task and respond a question. Finger tapping and fist-edge-palm were clumsy, and he had a difficulty in tandem gait. Deep tendon reflexes were generally brisk, but the ankle jerks were reduced. Other neurologic examinations were unremarkable. $\mathrm{T}_{2}$-weighted brain MRI showed diffuse high signal lesions in periventricular white matter involving principally in the frontal lobe (Fig. 1A). The electroencephalogram (EEG) showed diffuse bilateral theta activity without epileptiform discharge. The CSF and NCS were normal. $\mathrm{CD}_{4}$ T-lymphocyte counts were $10 / \mu \mathrm{L}(1 \%)$ and $\mathrm{CD}_{8}$ were $660 / \mu \mathrm{L}$ (70\%). Stereotaxic brainbiopsy done at the frontal white matter revealed demyelination with reactive astrocytosis, lipid- 

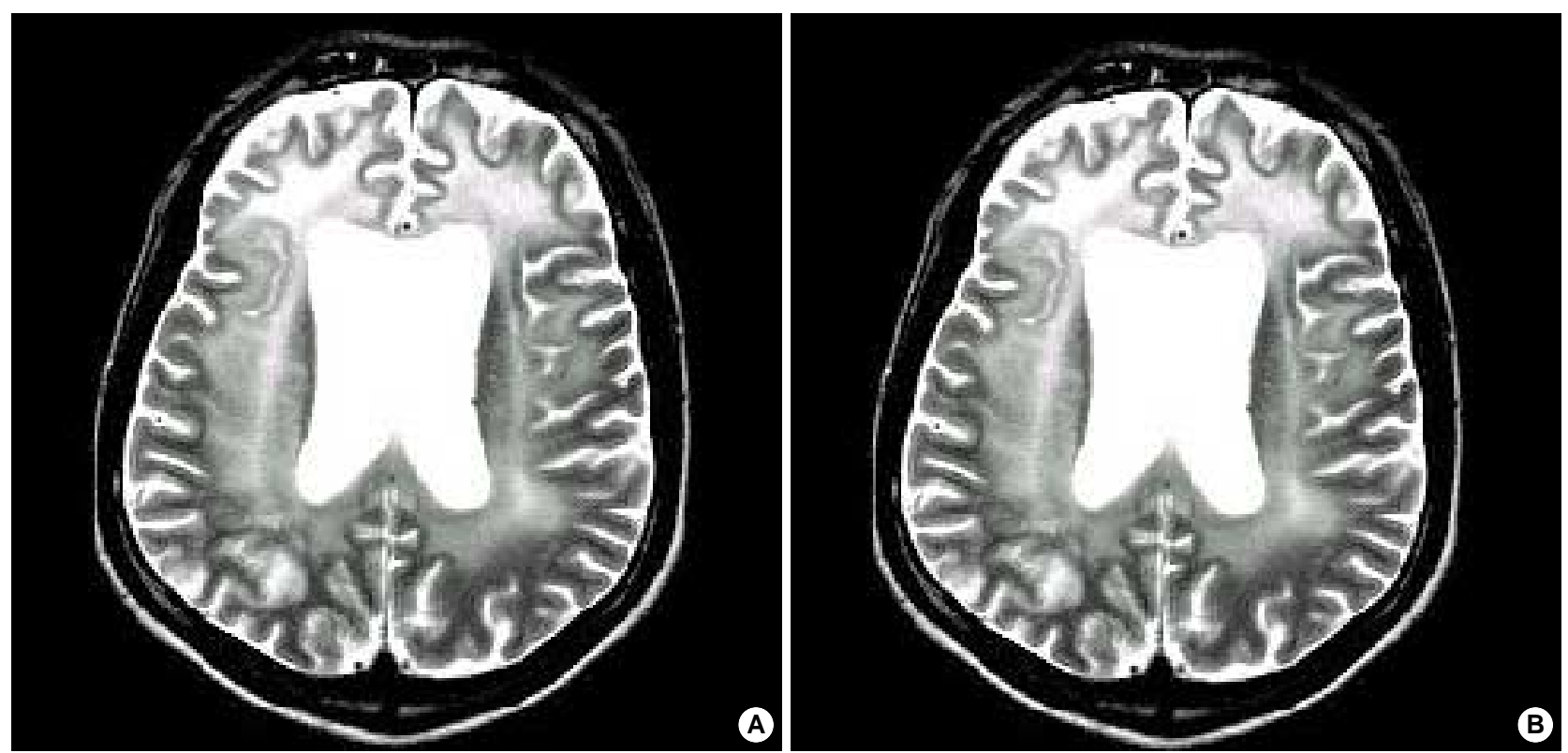

Fig. 1. T2-weighted brain magnetic resonance images at sixth $(A)$ and ninth $(B)$ month from the symptom onset (Case 1). Progressive bilateral diffuse white matter high signal intensities more severe in the frontal lobe and cortical atrophy with ventricular enlargement are noted.

laden macrophages, and multinucleated giant cell formation without definite intranuclear inclusion which was consistent with HIV-1 related white matter lesion. He was treated with zidovudine, but progressively deteriorated.

Three months after the initial evaluation he developed urinary incontinence and showed overt dementic features. Follow-up CSF analysis showed predominantly mononuclear pleocytosis, an elevated protein level with a normal glucose concentration. CSF VDRL, cultures, and cytology were negative. On follow-up MRI, the extent of diffuse confluent high signal intensity (HSI) on $\mathrm{T}_{2}$-weighted images $\left(\mathrm{T}_{2} \mathrm{WI}\right)$ and cortical atrophy increased (Fig. 1B).

Over the ensuing 2 months, he became increasingly demented. His verbal responses were slow, dysarthric, and reduced to simple phrases. Cognition was severely impaired in all areas, and there was spastic paraparesis with bilateral extensor plantar and grasp reflexes. He died 6 months after the initial evaluation. Autopsy was done and the neuropathologic findings were consistent with HIV dementia.

HIV-1-associated cognitive/motor complex was found in 10 patients: 1 biopsy-and autopsy-proven HIV dementia, 2 possible HIV dementias, and 7 possible HIV MCMD. Nine patients were at the clinical stage $\mathrm{C} 3$ and only one patient was at the clinical stage B2.

The most common early symptom was psychomotor slowing. Almost all patients had a variable amount of psychomotor slowing commonly accompanied by blunting of affect. The next common complaints were forgetfulness and decreased concentration (Table 3 ). Initially these symptoms were usually subtle. Therefore, most of patients did not recognize
Table 3. Common early symptoms and signs of HIV-1-associated cognitive/motor complex

\begin{tabular}{lc}
\hline SYMPTOMS & No. of patients \\
\hline Cognitive & 10 \\
Slowness of mental activities & 6 \\
Easy forgetfulness & 5 \\
Difficulty in concentration & \\
Motor & 2 \\
Clumsiness in fine motor coordination & 2 \\
Loss of balance & 1 \\
Tremor & \\
Behavioral & 6 \\
Apathy or social withdrawal & 1 \\
Agitated psychosis & 1 \\
Visual hallucination & 1 \\
Aggressive behavior & \\
Others & 2 \\
Headache & 2 \\
Brief loss of consciousness & \\
\hline SIGNS & 7 \\
\hline Generalized hyperreflexia & 6 \\
Slowing or clumsiness of RAM & 4 \\
Extensor plantar reflex & 3 \\
Frontal lobe release signs & 2 \\
Saccadic smooth pursuit of ocular movement & \\
\hline RAM: rapid atenatig movement & \\
\hline
\end{tabular}

RAM: rapid alternating movement.

the exact onset of the symptoms and sometimes many of these symptoms were only reported by patients' families or friends. However, when examined at advanced stages of HIV dementia, they showed characteristic clinical features including glob- 

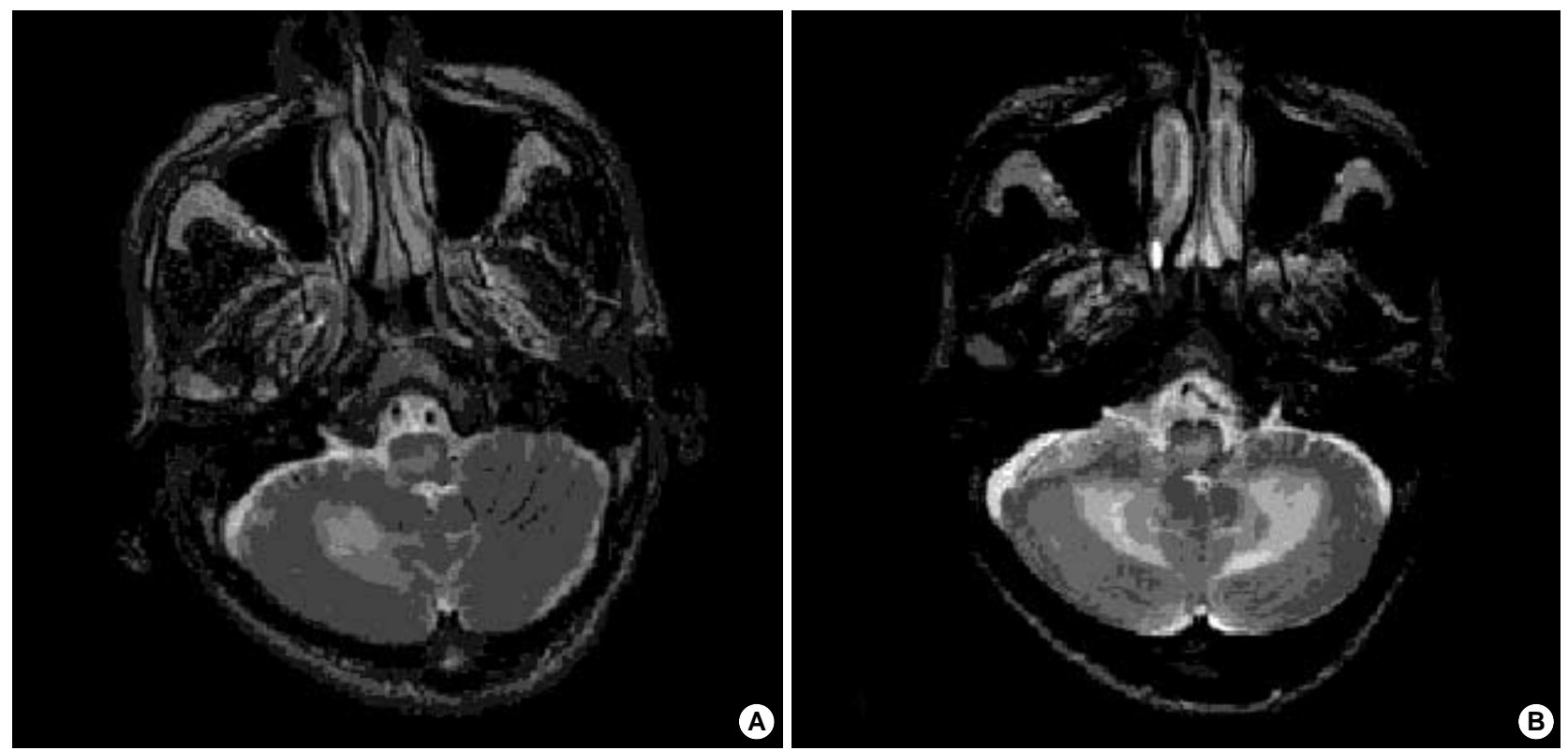

Fig. 2. T2-weighted brain magnetic resonance images at second month from the symptom onset (A), and one-month follow-up image (B) (Case 2). High signal intensities are noted in medulla and right cerebellar hemisphere, progressed to bilateral cerebellar hemispheric lesions.

al cognitive impairment.

On standard neurologic examination, most common abnormalities were pyramidal tract signs and clumsiness of rapid alternating movements (Table 3). Routine bedside MMSE was usually normal, although responses were commonly delayed. Five patients had a difficulty in performing serial 7's and in recalling a series of objects after $5 \mathrm{~min}$. On detailed neuropsychologic examination, motor functioning and speed of processing were most severely impaired and memory, abstract thinking, attention, and concentration were also commonly abnormal, while visuospatial function and language were relatively spared. In case with memory deficit, almost all patients had more difficulty in free recall than recognition.

Brain MRI was performed in 3 patients with HIV dementia and 1 patient with HIV MCMD. In all cases, MRI showed various amounts of diffuse cortical atrophy and ventricular enlargement. In two, MRI revealed diffuse periventricular HSI on $\mathrm{T}_{2}$ WI. CSF study was performed in only one patient. The findings are described in case 1 .

\section{Focal CNS complications}

\section{CASE 2}

A 38-yr-old HIV-1-seropositive male was admitted because of severe vertigo, dysarthria, and dysphasia that had gradually developed and progressed over 1 month. He had a history of tuberculous lymphadenitis and was suffering from herpes zoster on his left chest. Neurologic examinations revealed bilateral gaze evoked nystagmus and dysmetria more on the right side. Right facial sensation was a little decreased and tongue and palatine movement was severely impaired.

Other cranial nerves, sensation, and strength were normal. Deep tendon reflexes were generally brisk, but there was no Babinski sign. Gait was very ataxic. Neither Horner's signs nor neck stiffness was present. The $\mathrm{CD}_{4} \mathrm{~T}$-lymphocyte count was $40 / \mu \mathrm{L}$. Brain MRI showed patch nonenhancing HSI on $\mathrm{T}_{2} \mathrm{WI}$ in bilateral medulla and right cerebellum (Fig. 2A). Viral and Toxoplasma antibody studies were negative. CSF was acellular with normal protein and glucose levels. All other CSF studies including VDRL, cultures, and cytology were negative. Empirical therapy with trimethoprim/sulfamethoxazol and acyclovir were ineffective. Presumptively, the diagnosis of progressive multifocal leukoencephalopathy (PML) in the posterior fossa was made. On follow-up MRI, the extent of the lesion was increased (Fig. 2). MR angiography showed no remarkable findings. Follow-up CSF study was normal, however, JC virus DNA was detected in the CSF by polymerase chain reaction. His symptoms worsened progressively and he died about one year after the onset.

Three patients (8.8\%) showed focal brain lesions. Two were presumptively diagnosed as having primary CNS lymphoma, and 1 as having PML in the posterior fossa, based on history, clinical findings, serology, radiological appearances, and response to empirical therapy. However, the definite diagnoses were not made due to the lack of pathologic confirmation.

All patients were at the clinical stage C 3 . None had a positive serologic test for toxoplasmosis or successful response to antitoxoplasmosis therapy. The clinical features in 3 patients with focal CNS complications are outlined in Table 4. 
Table 4. The clinical features in 3 HIV-1 (+) patients with focal CNS complications

\begin{tabular}{|c|c|c|c|c|c|c|c|c|}
\hline $\begin{array}{l}\text { Sex/ } \\
\text { Age (yr) }\end{array}$ & Risk factor & $\begin{array}{l}\text { Symptoms \& } \\
\text { signs }\end{array}$ & $\begin{array}{c}\text { Associated } \\
\text { conditions }\end{array}$ & $\begin{array}{l}\text { Clinical } \\
\text { stage }\end{array}$ & $\begin{array}{c}\text { CD4 } \\
\text { count }(/ \mu \mathrm{L})\end{array}$ & CSF & Brain MRI & Outcome \\
\hline M/38 & Bisexual & $\begin{array}{l}\text { Vertigo, dysarthria } \\
\text { dysphagia, } \\
\text { gait disturbance, } \\
\text { ataxia }\end{array}$ & $\begin{array}{l}\text { Herpes zoster, } \\
\text { Tbc lymphadenitis, } \\
\text { CMV retinitis }\end{array}$ & C3 & 70 & $\begin{array}{l}\text { Normal } \\
\text { JC virus DNA } \\
(+) \text { by PCR }\end{array}$ & $\begin{array}{l}\text { Nonenhancing } \\
\text { lesion at medullar } \\
\text { and cbll (Fig. 1) }\end{array}$ & Death \\
\hline $\mathrm{M} / 44$ & Heterosexual & $\begin{array}{l}\text { Lt V/F defect, } \\
\text { dysarthria, } \\
\text { foot sensory loss, } \\
\text { b/l Babinski signs }\end{array}$ & $\begin{array}{l}\text { Pulm Tbc, CMV retinitis } \\
\text { DSP, cryptococcal- } \\
\text { mgts, molluscum- } \\
\text { contagiosum }\end{array}$ & s, 3 & 10 & Traum & $\begin{array}{l}\text { Enhancing mass } \\
\text { at Rt occipital } \\
\text { (Fig. 2) }\end{array}$ & $\begin{array}{l}\text { Sudden respi- } \\
\text { ratory arrest }\end{array}$ \\
\hline M/35 & Heterosexual & $\begin{array}{l}\text { Rt FP \& hemiparesis, } \\
\text { memory loss, } \\
\text { generaliezed } \\
\text { hyperreflexia }\end{array}$ & $\begin{array}{l}\text { Herpes zoster, PCP } \\
\text { CMV esophagitis }\end{array}$ & C3 & 30 & $\begin{array}{l}\text { Elevated } \\
\text { protein level }\end{array}$ & $\begin{array}{l}\text { Multifocal enha- } \\
\text { ncing } \\
\text { lesions with Hmr. } \\
\text { at CC, Lt Parietal } \\
\text { \& thalamus }\end{array}$ & $\begin{array}{l}\text { Rt weakness } \\
\& \text { ataxia, } \\
\text { incontinence }\end{array}$ \\
\hline
\end{tabular}

Lt: left, V/F: visual field, b/l: bilateral, Rt: right, FP: facial palsy, Tbc: tuberculosis, CMV: cytomegalovirus, Pulm: pulmonary, DSP: distal symmetric polyneuropathy, mgts: meningitis, PCP: Pneumocystis carinii pneumonia, PCR: polymerase chain reaction, Cbll: cerebellum, Hmr: hemorrhage, CC: corpus callosum.

\section{Neuromuscular complications}

\section{CASE 3}

A 38-yr-old male was admitted with a 2-month history of fever and burning pain on both soles. After investigation, diagnoses of Pneumocystis carinii pneumonia and esophageal candidiasis were made and HIV-1 infection was confirmed by Western blot. His $\mathrm{CD}_{4} \mathrm{~T}$-lymphocyte count was $20 / \mu \mathrm{L}$. Neurologic examination showed distal-to-proximal sensory gradient in the lower extremities and decreased ankle jerks. Knee jerks were somewhat brisk and Babinski sign was positive. Other neurologic examinations including muscle strength were normal. NCS showed markedly decreased amplitude of compound muscle action potential (CMAP) and sensory nerve action potential (SNAP), and the slowing of nerve conduction velocity (NCV), which was more severe on the lower extremities without any evidence of spontaneous activity on EMG. Other biochemical and serologic studies including vitamin B12 were normal. Amitriptyline was tried with a limited effect.

Neuromuscular complications were found in 10 patients. Nine patients had distal symmetric polyneuropathy (DSP): 7 were symptomatic and 2 asymptomatic. One patient was presumptively diagnosed as chronic inflammatory demyelinating polyradiculoneuropathy (CIDP). He presented with progressive symmetric weakness on four extremities (lower $>$ upper extremity, proximal >distal). He has not been treated with zidovudine. The serum creatine kinase level was normal. Electrophysiologic study showed conduction block without any evidence of myopathy. However, the final diagnosis was not made because he refused further evaluation.

Among the 10 patients, 9 were at the clinical stage $\mathrm{C} 3$ and 1 was at the clinical stage B2. None had an abnormal vita- min B12 level or uncorrectable anemia or a history of treatment with neurotoxic antiviral agents more than 3 months.

In the 9 patients with distal symmetric polyneuropathy (DSP), the most common complaint was tingling or burning pain in the soles of feet (7 patients), followed by numbness (4 patients) and weakness (1 patient) of the feet. These symptoms were usually confined to the ankles, although sensory examinations were abnormal above the ankles. Only one patient had the symptoms extended above the ankles. Symmetric complaints were the rule, although one patient had the symptom on one foot at onset but the other one rapidly became similarly affected. On neurologic examination, ankle jerks were exclusively absent or decreased (9 patients). Also, there was a marked discrepancy between knee and ankle jerks with the former being excessively brisk compared to the latter (6 patients). Four patients show a distal-to-proximal gradient to light touch, pinprick, and coldness in the lower extremities. However, strength and position sensation were relatively preserved in all patients except one who had severe polyneuropathy. Electrophysiologic studies showed features of an axonal degeneration with variable degrees of demyelination suggestive of a dying-back axonopathy. In spite of the predominantly sensory complaints, 6 patients had a sensorimotor polyneuropathy and only 3 had a predominantly sensory polyneuropathy.

\section{Other complications}

One patient had cryptococcal meningitis, which was successfully treated by amphotericin B. Two patients had pyramidal tract signs without any neurologic diseases. Four patients had paresthesia on the soles without electrophysiologic evidence of peripheral neuropathy. However, all these patients 
had a marked discrepancy between knee and ankle jerks.

\section{DISCUSSION}

The results showed that 17 (50\%) out of 34 HIV-1 seropositive patients had neurologic complications and $3(9 \%)$ presented with neurologic complaints. Our figure is a little higher than that of other major series $(4,5)$. This seems to have stemmed from the fact that our patients were skewed toward the more advanced stage that commonly occurs in inpatient populations. This was more evident if we analyzed the patients into two groups as more advanced stage (clinical stage C3) and less advanced stage (clinical stage less than C3): $15(68 \%)$ out of 22 patients in the former, whereas only 2 $(17 \%)$ out of 12 patients in the latter had neurologic complications. Other clinical parameters including age, hemoglobin, $\beta 2$-microglobulin, and disease duration were not significantly different between the two groups (data not shown). A significant difference was observed only in the CD4 T-lymphocyte count (51 vs $426 / \mu \mathrm{L}$ ). Therefore, it was clear that the neurologic complications of HIV-1 infection increased with advancing immunosuppression, in parallel with decreasing CD4 T-lymphocyte count.

In this study, one of the most common neurologic complications of HIV-1 infection was cognitive/motor impairment (29\%). It has been known under a variety of terms including AIDS dementia complex, HIV encephalopathy, subacute encephalitis, and currently, HIV-1-associated cognitive/motor complex.

The HIV-1-associated cognitive/motor complex may range from subtle cognitive abnormalities to a severe dementia. Working group of American Academy of Neurology AIDS Task Force divided it into two clinical categories as HIV-1associated dementia complex (HIV dementia) and HIV-1associated cognitive/motor disorders (HIV MCMD) (15). The former occurs in advanced stages of HIV-1 infection and is an AIDS defining manifestation with a variety of dementic symptoms and signs, while the latter does not meet the usual criteria for dementia because activities of daily living are not compromised. The two may represent two ends of a single disease entity with a broad spectrum of clinical presentations and severity, so patients with a milder form will invariably progress to a severe form as was one of our patients who was initially diagnosed as HIV MCMD and finally progressed to full blown HIV dementia (case 1). However, it is also suggested that only a small percentage of patients who diagnosed as HIV MCMD would progress to HIV dementia on follow-up testing and the majority of them reverted to normal neuropsychological test performance or subclinical cognitive impairment (16). Thus, at present, it is not clear whether HIV MCMD represents a milder form of HIV dementia or the pathophysiology of these disorders are different.

In this study, 3 patients (14\%) out of 22 at advanced stages of HIV-1 infection showed HIV dementia. The prevalence of HIV dementia has been reported to range from $7 \%$ to $90 \%$ (17). Such a big difference was caused by the heterogeneity of the population with respect to the stage of HIV-1 infection and by the variation in the clinical cut-off used to diagnose dementia. Now, it is generally accepted that HIV dementia occurs in approximately 20 to $30 \%$ of patients with advanced HIV-1 infection (18) and the annual incidence is about $7 \%$ per year after development of AIDS (18-20).

The clinical features of 10 patients with HIV-1-associated cognitive/motor complex were similar to the previous descriptions and suggested predominantly subcortical involvement at least initially (18). Most characteristic early manifestation was psychomotor slowing. Thus, it was not unusual that routine MMSE was normal in most of our patients, because MMSE does not include any subsets for evaluation of psychomotor speed. Other common early symptoms were easy forgetfulness, difficulty in concentration, and waning interest in work and hobbies resulting in social withdrawal. The friends or family members of the patients often reported less common behavioral abnormalities such as shifts in personality with apathy and social withdrawal and blunting of emotional responsiveness. Common motor complaints included poor handwriting, insecure balance, and clumsiness. However, other higher cortical functions were usually preserved until the dementia is far advanced. The course is usually progressive and most reports have described typical survivals of about 6 to 12 months once the syndrome occurred $(18,21)$.

No laboratory or neuroimaging study is diagnostic for HIV dementia so far. Thus, the diagnosis is based on the typical clinical features and the exclusion of other conditions such as opportunistic infections and metabolic abnormalities as alternative explanations for the syndrome. At the early stage of disease, the diagnosis is not easy because the initial symptoms can be confused with depression, anxiety disorder, or the effects of psychoactive substances. Brain imaging is necessary to exclude other infectious or neoplastic diseases. The most common findings of brain MRI is nonspecific cerebral atrophy with or without periventricular white matter signal abnormalities on $\mathrm{T}_{2} \mathrm{WI}(21,23,24)$. However, brain imaging may be normal $(21,23)$. CSF study is also essential to rule out opportunistic infections and syphilis. CSF abnormalities such as elevated protein, mild mononuclear pleocytosis, intrathecal synthesis of anti-HIV IgG, and oligoclonal band are common. However, these abnormalities are nonspecific because similar CSF abnormalities can be found in asymptomatic HIV-1-seropositive patients (25). Furthermore, CSF can be normal, too.

The common neuropathologic findings include multinucleated giant cells, microglial nodules and perivenular inflammation (HIV encephalitis), and diffuse pallor of the myelin and reactive astrocytosis (HIV leukoencephalopathy) (22). In general the number of nodules does not correlate with the severity of the dementia (22), whereas multinucleated giant 
cells derived from macrophages that yield HIV-1 DNA or antigens correlate with the severity of the dementia (26).

However, not all the patients with dementia showed these changes and the pathologic changes may be often less prominent than clinical symptoms (27).

The pathogenesis of HIV dementia remains unknown. Even in patients with severe dementia, there may be only mild neuropathologic changes and only a small fraction of cells within inflammatory nodules or periventricular infiltrates contain viral antigens. This discrepancy between the small amounts of replicating HIV-1 and the severity of the dementia suggests that other factors besides direct cellular damage by HIV-1 may be of importance in pathogenesis.

Despite many unresolved questions in pathogenesis, antiretroviral agents are currently used in the treatment of HIV dementia. At present, zidovudine is the only antiretroviral agent that has been proven to be effective as documented by anecdotal case reports $(28,29)$, open-label observation study (30), and placebo-controlled trial (31). However, the optimal dose of zidovudine has not been determined. Recently, the combination therapy of antiretroviral agents is under investigation, which is already proven in systemic disease. Other non-antiviral agents such as memantine (open channel NMDA antagonist), pentoxyphylline (tumor necrosis factor antagonist), and peptide $\mathrm{T}$ (pentapeptide analog of gp120) are also being explored.

The most important differential diagnosis of focal CNS lesions in patients with HIV-1 infection include cerebral toxoplasmosis, primary CNS lymphoma, and PML. Less frquently tuberculous or fungal abscess, focal viral encephalitis, metastatic Kaposi's sarcoma or systemic lymphoma, stroke, and late HIV-1 associate dementia complex can cause focal CNS lesions.

In general, the diagnosis can be made efficiently by clinical presentation, neuroimaging, serology, and response to therapy. With respect to temporal progression, cerebral toxoplasmosis usually evolves most rapidly over a few days to weeks. PML is the most indolent, evolving several weeks, while primary CNS lymphoma pursues an intermediate course (32). Neuroimaging is most helpful to detect and differentiate these diseases. PML lesions neither cause a mass effect nor enhance, whereas mass effect and enhancement are often noted in the lesion of toxoplasmosis and lymphoma. The contrast enhancement is usually more distinct and ring-shaped in toxoplasmosis and more diffuse in lymphoma. In addition, toxoplasma abscess usually occurs in the gray matter of the diencephalon and cortex whereas lymphoma commonly involves the deep white matter adjacent to the ventricles (32, 33). However, this is not always the rule. Thus, definitive diagnosis often requires neuropathologic confirmation, especially after an unsuccessful trial of anti-Toxoplasma therapy (34).

In this study, 3 patients $(8.8 \%)$ showed focal CNS lesions. One patient (case 2) had slowly progressive brain stem and cerebellar dysfunctions. Brain MRI showed nonenhancing lesions in compatable location with his dysfunctions. Other investigations and empirical therapy showed no evidences of opportunistic infection or vasculitis. Thus, the patient was diagnosed as possible PML in the posterior fossa, which is not as common as that of hemisphere. Later, JC virus DNA was detected in the patient's CSF by PCR. Recently, besides JC virus, $\mathrm{PCR}$ is used as a promising diagnostic tool to detect Toxoplasma and Epstein-Barr virus DNA in CSF (35-38).

The other two patients had enhancing mass lesions with only reluctant signs. The clinical presentation favored primary CNS lymphoma than toxoplasmosis. Moreover, neither patients were positive for Toxoplasma antibody or responsive to anti-Toxoplasma therapy. Thus, they were presumptively diagnosed as possible primary CNS lymphoma although an absence of antibody and unsuccessful anti-Toxoplasma therapy could not completely exclude the diagnosis of toxoplasmosis.

Finally, none had cerebral toxoplasmosis that has been known to be the most common focal CNS lesion $(4,6,39)$. Thus, it is likely that the pattern of opportunistic CNS infection in Korean HIV-1 seropositive populations is different from that of other countries $(4,5,41,42)$, although a Korean patient of AIDS with cerebral toxoplasmos was reported (43).

Neuromuscular complications have not received as much attention as CNS complications because the latter constitute the most significant neurologic complications in terms of morbidity and mortality. However, neuromuscular complications are also common and important causes of morbidity.

There are three kinds of main neuropathic syndromes in HIV-1 infection: (1) a distal symmetric polyneuropathy (DSP) with predominantly sensory symptoms that usually occur at the late stage of infection, (2) an inflammatory demyelinating polyradiculoneuropathy (IDP) that may occur acutely as a seroconversion reaction or chronically at early or intermediate stage of infection, and (3) mononeuropathy multiplex that occurs at all stage of infection.

Of these, DSP has been reported as the most frequently encountered syndrome and clinical and electrophysiologic abnormalities consistent with DSP may be detected in about one third of patients (40). At autopsy, however, neuropathologic evidences of DSP may be found in the majority of the AIDS patients (41). This study proved that DSP is the most common neuromuscular complication, even though its frequency $(26 \%)$ is a little less than that of the previous report (40).

The clinical features of 9 patients with DSP were also similar with those in the previous report, characterized with initial complaints of paresthesia or numbness almost always beginning in the soles and gradually ascending $(4,41,44)$. The most common sign is depressed or absent ankle jerks relative to knee jerks. In addition, a marked discrepancy between knee and ankle jerks is another common early sign, which may indicate concurrent CNS pathology. The electrophysiologic features were indicative of distal symmetric degeneration of 
sensory and motor axons, with a similar pattern of other forms of DSP.

Although the clinical features of DSP are characteristic, they are not pathognomonic because some antiretroviral nucleosides, including didanosine, zalcitabine, and stavudine, cause similar neuropathy (45). In addition, vitamin B12 deficiency, administration of isoniazid for mycobacterial infection and vitamin B6 deficiency can also cause similar neuropathy. However, none of the patients with DSP were treated with neurotoxic antiviral agents more than 3 months or had other causes of peripheral neuropathy, it is likely that their DSP resulted from the complication of HIV-1 infection.

Like HIV dementia, the pathogenesis of DSP is still unknown. Since HIV is not detected systematically within affected fibers, cytokine-mediated toxic effect has been hypothesized (46).

The therapy for DSP is limited at present and only directed at symptoms relief. In contrast to HIV dementia, zidovudine has not shown consistent benefit toward neuropathic symptoms despite responses of other disease markers (47). The impact of other antiretroviral agents that are not neurotoxic is unknown.

The other important neuromuscular complication of HIV1 infection is IDP. Clinically, HIV-1-associated IDP is indistinguishable from idiopathic IDP. However, in contrast to the classic CSF profiles of increased protein in the absence of pleocytosis, HIV-1-associated IDP is associated with mild lymphocytic pleocytosis (48). It is treated in a manner similar to that used in patients without HIV-1 infection and the prognosis is generally good $(48,49)$. In this study, one patient showed typical clinical and electrophysiologic pictures of CIDP. Unfortunately, however, we could not make a final diagnosis, because of lack of the CSF results and treatment response.

It should be mentioned that some caution must be applied to the interpretation of this study because this was a primarily cross-sectional study even though clinical follow-up was possible in some patients and pathologic confirmation was not obtained in most of patients. Therefore, our results might be different from the real incidence or prevalence of neurologic complications in HIV-1 seropositive Korean populations. However, these data are of value in giving an overview of relative frequencies and characteristic clinical features of neurologic complications.

In this population of Korean inpatients with HIV-1 infection, the neurologic complications were frequent and diverse, often with multiple etiologies in a single patient. They increased with advancing immunosuppression, in parallel with the decreasing CD4 T-lymphocyte count. General features and frequencies of them were not so different from those observed in other countries. An important exception is that none had cerebral toxoplasmosis.

Even in the absence of neurologic complaints, these patients should be carefully questioned and examined in search for underlying neurologic complications that may present high morbidity and mortality.

\section{REFERENCES}

1. Centers for Disease Control and Prevention. Kaposi's sarcoma and Pneumocystis pneumonia among homosexual men-New York City and California. MMWR 1981; 30: 305-8.

2. Gottlieb MS, Schanker HM, Fan PT. Pneumocystis carinii pneumonia-Los Angeles. MMWR 1981; 30: 250-2

3. Mertens TE, Low-Beer D. HIV and AIDS: Where is the epidemic going? Bull World Health Org 1996; 74: 121-9.

4. Snider WD, Simpson DM, Nielsen S, Gold JW, Metroka CE, Posner JB. Neurological complications of acquired immune deficiency syndrome: analysis of 50 patients. Ann Neurol 1983; 14: 403-18.

5. Levy RM, Bredesen DE, Rosemblum ML. Neurological manifestations of the acquired immunodeficiency syndrome (AIDS): experience at UCSF and review of the literature. J Neurosurg 1985; 62. 475-95.

6. McArthur JC. Neurologic manifestations of AIDS. Medicine (Baltimore) 1987; 66: 407-37.

7. Berger JR, Moskowitz L, Fischl M, Kelley RE. Neurologic disease as the presenting manifestation of acquired immunodeficiency syndrome. South Med J 1987; 80: 683-6.

8. Petito CK, Cho ES, Lemann W, Navia BA, Price RW. Neuropathology of acquired immunodeficiency syndrome (AIDS): an autopsy review. J Neuropathol Exp Neurol 1986; 45: 635-46.

9. Gray F, Gherardi R, Scaravilli F. The neuropathology of the acquired immune deficiency syndrome (AIDS). A review. Brain 1988; 111: 245-66.

10. Lang W, Miklossy J, Deruaz JP, Pizzolato GP, Probst A, Schaffner T, Gessaga E, Kleihues P. Neuropathology of the acquired immune deficiency syndrome (AIDS): a report of 135 consecutive autopsy cases from Switzerland. Acta Neuropathol (Berl) 1989; 77: 379-90.

11. Lantos PL, McLaughlin JE, Schoitz CL, Berry CL, Tighe JR. Neuropathology of the brain in HIV infection. Lancet 1989; 11: 309-11.

12. Burns DK, Risser RC, White CL III. The neuropathology of human immunodeficiency virus infection. The Dallas, Texas, experience. Arch Pathol Lab Med 1991; 115: 1112-4.

13. Oh MD, Choe K. Epidemiology of HIV infection in the Republic of Korea. J Korean Med Sci 1999; 14: 469-74.

14. Anonymous. 1993 revised classification system for HIV infection and expanded surveillance case definition for AIDS among adolescents and adults. MMWR 1992; 41: 1-19.

15. Report of a Working Group of the American Academy of Neurology AIDS Task Force. Nomenclature and research case definitions for neurologic manifestations of human immunodeficiency virus type 1 (HIV-1) infection. Neurology 1991; 41: 778-85.

16. McArthur JC, Grant I. HIV Neurocognitive disorders, The Neurology of AIDS. Edited by Gendelman HE, Lipton SA, Epstein L, Swindells S. New York, Chapman \& Hall 1998: 499-523.

17. Brew BJ. Central and peripheral nervous system abnormalities in HIV-1 infection. In Medical Management of AIDS patients. Med Clin North Ame Saunders Philadelphia 1992; 76: 63-81. 
18. McArthur JC, Hoover DR, Bacellar H, Miller EN, Cohen BA, Becker JT, Graham NM, McArihur JH, Selnes OA, Jacobson JP, et al. Dementia in AIDS pa-tients: Incidence and risk factors. Neurology 1993; 43: 2245-52.

19. Janssen RS, Nwanyanwu OC, Selik RM, Stehr-Green JK. Epidemiology of human immunodeficiency virus encephalopathy in the United States. Neurology 1992; 42: 1472-6.

20. Bacellar H, Munoz A, Miller EN, Cohen BA, Besley D, Selnes OA, Becker JT, McArthur JC. Temporal trends in the incidence of HIV1-related neurologic diseases: Multicenter AIDS Cohort Study, 19851992. Neurology 1994; 44; 1892-900.

21. Navia BA, Jordan BD, Price RW. The AIDS dementia complex: I. Clinical features. Ann Neurol 1986; 19: 517-24.

22. Navia BA, Cho ES, Petito CK, Price RW. The AIDS dementia complex: II. Neuropathology. Ann Neurol 1986; 19: 525-35.

23. Post MJ, Tate LG, Quencer RM, Hensley GT, Berger JR, Sheremata WA, Maul G. CT, MR, and pathology in HIV encephalitis and meningitis. AJR Am J Roentgenol 1988; 151: 373-80.

24. Olsen WL, Longo FM, Mills CM, Norman D. White matter disease in AIDS: findings at MR imaging. Radiology 1988; 169: 445-8.

25. Marshall DW, Brey RL, Cahill WT, Houk RW, Zajac RA, Boswell RN. Spectrum of cerebrospinal fluid findings in various stages of human immunodeficiency virus infection. Arch Neurol 1988; 45: 954-8.

26. Price RW, Sidtis J, Rosenblum M. AIDS dementia complex: some current questions. Ann Neurol 1988; 23: S27-33.

27. Glass JD, Wesselingh SL, Selnes OA, McArthur JC. Clinical-neuropathologic correlation in HIV-associated dementia. Neurology 1993; 43: 2230-7.

28. Yarchoan R, Berg G, Brouwers P, Fischl MA, Spitzer AR, Wichman A, Grafman J, Thomas RV, Safai B, Brunetti A. Response of humanimmunodeficiency-virus-associated neurological disease to 3'-azido3'-deoxythymidine. Lancet 1987; 1: 132-5.

29. Sobanski T, Assion HJ, Scholl HP, Hoflich G, Laux G. Successful zidovudine (AZT) treatment in a case of human immunodeficiency virus (HIV)-1-associated dementia complex. Biol Psychiatry 1996; 39: $1065-6$.

30. Tozzi V, Narciso P, Galgani S, Sette P, Balestra P, Gerace C, Pau FM, Pigorini F, Volpini V, Camporiondo MP, et al. Effects of zidovudine in 30 patients with mild to end-stage AIDS dementia complex. AIDS 1993; 7: 683-92.

31. Sidtis JJ, Gatsonis C, Price RW, Singer EJ, Collier AC, Richman DD, Hirsch MS, Schaerf FW, Fischl MA, Kieburtz K. Zidovudine treatment of the AIDS dementia complex: results of a placebo controlled trial. Ann Neurol 1993; 33: 343-9.

32. Price RW. Neurological complications of HIV infection. Lancet 1996; 17: 445-52.

33. Steinmetz H, Arendt G, Hefter H, Neuen-Jacob E, Dorries K, Aulich A, Kahn T. Focal brain lesions in patients with AIDS: aetiologies and corresponding radiological patterns in a prospective study. J Neurol 1995; 242: 69-74.

34. Ciricillo SF, Rosenblum ML. Use of CT and MR imaging to distinguish intracranial lesions and to define the need for biopsy in AIDS patients. J Neurosurg 1990; 73: 720-4.

35. De Luca A, Cingolani A, Linzalone A, Ammassari A, Murri R, Giancola ML, Maiuro G, Antinori A. Improved detection of JC virus DNA in cerebrospinal fluid for diagnosis of AIDS-related progressive multifocal leukoencephalopathy. J Clin Microbiol 1996; 34: 1343-6.

36. Hammarin AL, Bogdanovic G, Svedhem V, Pirskanen R, Morfeldt $\mathrm{L}$, Grandien M. Analysis of PCR as a tool for detection of JC virus DNA in cerebrospinal fluid for diagnosis of progressive multifocal leukoencephalopathy. J Clin Microbiol 1996; 34: 2929-32.

37. Cinque P, Vago L, Dahl H, Brytting M, Terreni MR, Fornara C, Racca S, Castagna A, Monforte AD, Wahren B, Lazzarin A, Linde A. Polymerase chain reaction on cerebrospinal fluid for diagnosis of virusassociated opportunistic diseases of the central nervous system in HIVinfected patients. AIDS 1996; 10: 951-8.

38. Tachikawa N, Goto M, Hoshino Y, Gatanaga H, Yasuoka A,Wakabayashi T, Katano H, Kimura S, Oka S, Iwamoto A. Detection of Toxoplasma gondii, Epstein-Barr virus, and JC virus DNAs in the cerebrospinal fluid in acquired immunodeficiency syndrome patients with focal central nervous system complications. Intern Med 1999; 38: 556-62.

39. Porter SB, Sande MA. Toxoplasmic encephalitis in AIDS. Clin Infect Dis 1992; 15: 211-22.

40. So YT, Holtzman DM, Abrams DI, Olney RK. Peripheral neuropathy associated with acquired immunodeficiency syndrome. Prevalence and clinical features from a population-based survey. Arch Neurol 1988; 45: 945-8.

41. Simpson DM, Tagliati M. Neurologic manifestation of HIV infection. Ann Intern Med 1994; 121: 769-85.

42. Oh MD, Park SW, Kim HB, Kim US, Kim NJ, Choi HJ, Shin DH, Lee JS, Choe K. Spectrum of opportunistic infections and malignancies in patients with human immunodeficiency virus infection in South Korea. Clin Infect Dis 1999; 29: 1524-8.

43. Sim MK, Park JH, Yu HS, Park KH, Ko JS, Bae WK, Shin JH, Kim SJ, Shin DH. A case of toxoplasmic encephalitis in an advanced AIDS patient. Korean J Inf Dis 2002; 34: 337-40.

44. Simpson DM. Neuromuscular complications of human immunodeficiency virus infection. Sem Neurol 1992; 12: 34-42.

45. Simpson DM, Tagliati M. Nucleoside analogue-associated peripheral neuropathy in human immunodeficiency virus infection. J Acquir Immune Defic Syndr Hum Retrovirol 1995; 9: 153-61.

46. Shapshak P, Nagano I, Xin K, Bradley W, McCoy CB, Sun NC, Stewart RV, Yoshioka M, Petito C, Goodkin K. HIV-1 heterogeneity and cytokines. Neuropathogenesis. Adv Exp Med Biol 1995; 373: 225-38.

47. Cornblath DR, McArthur JC. Predominantly sensory neuropathy in patients with AIDS and AIDS-related complex. Neurology 1988; 38: 794-6.

48. Cornblath DR, McArthur JC, Kennedy PG, Witte AS, Griffin JW. Inflammatory demyelinating peripheral neuropathies associated with human T-cell lymphotropic virus type III infection. Ann Neurol 1987; 21: $32-40$.

49. Lange DJ. AAEM minimonograph \#41: neuromuscular diseases associated with HIV-1 infection. Muscle Nerve 1994; 17: 16-30. 